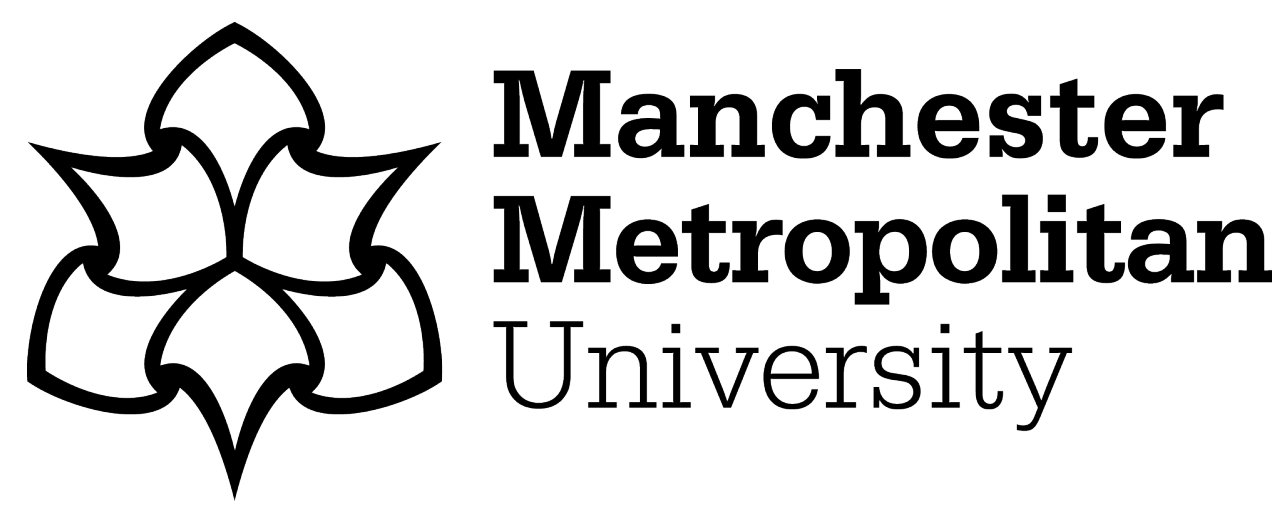

Sheen, KA ORCID logoORCID: https://orcid.org/0000-0002-6326-3241, Wong, MS, Kam, R, Kwok, CYT and Lu, K (2018) Gauging the Student Learning Experience of a Mobile Application Using iBeacon Technology. In: Advances in Physical Ergonomics \& Human Factors. International Conference on Applied Human Factors and Ergonomics (AHFE 2018), 21 July 2018 - 25 July 2018, Orlando, USA.

Downloaded from: https://e-space.mmu.ac.uk/625469/

Publisher: Springer

DOI: https://doi.org/10.1007/978-3-319-94484-5_5

Please cite the published version 


\title{
Gauging the Student Learning Experience of a Mobile Application Using iBeacon Technology
}

\author{
Kimberly Anne Sheen ${ }^{1}$, Man Sing Wong ${ }^{1, *}$, Roy Kam², Coco Y.T. Kwok ${ }^{1}$, and Keru \\ $\mathrm{Lu}^{1}$ \\ ${ }^{1}$ Department of Land Surveying and Geo-Informatics, The Hong Kong Polytechnic Univer- \\ sity, Hung Hom, Kowloon, Hong Kong SAR \\ \{kaasheen, ls.charles\}@polyu.edu.hk; \{yt-coco.kwok, keru.lu\}@connect.polyu.hk \\ ${ }^{2}$ eLearning Development and Support Section, Educational Development Centre, The Hong \\ Kong Polytechnic University, Hung Hom, Kowloon, Hong Kong SAR \\ roy.kam@polyu.edu.hk
}

\begin{abstract}
Innovative technology has been revolutionizing the educational experience in tertiary institutions over the past decades. Using novel iBeacon Technology, a mobile application called "iClassPolyU” was developed for collecting and disseminating information to and from students. The application was employed in four medium to large classrooms and the user experience was evaluated through a survey. Usage of the application was examined through quiz completion and usage rates. Results showed that each class had a quiz completion rate of over $80 \%$. Moreover, students believed that their physical participation could be enhanced by the application and that it was effective, easy to use, and flexible. Students proposed the inclusion of mixed reality, virtual reality, and augmented reality in the future. This type of technology provides another pathway for student learning, an opportunity to give students more control over their learning, and educators with more information regarding their students.
\end{abstract}

Keywords: Educational technology · iBeacon/BLE technology · Online Survey · Mobile application · eLearning technology

\section{Introduction}

Academic achievement is often related to the amount of time and effort students take to engage with their learning materials. In fact, students who engage more with materials and institutions which emphasize engagement show a positive association with academic success [1-5]. Moreover, there are many pedagogies that aim to engage students

\footnotetext{
* Please note that the LNCS Editorial assumes that all authors have used the western naming convention, with given names preceding surnames (first name then last name). This determines the structure of the names in the running heads and the author index. No academic titles or descriptions of academic positions should be included in the addresses. The affiliations should consist of the author's institution, town, and country.
} 
more in learning [6], different types of group work [7], peer instruction [8], writing to learn and learning to write activities [9], and active learning [10]. These are regularly advocated to teachers in higher education for achieving improved academic outcomes for students. Teachers are now expected to be "less an imparter of knowledge and more a designer and facilitator of learning experiences and opportunities” [11]. Despite the apparent positive values of student engagement, encouraging teachers and institutions to engage students more in learning in-class and out-of-class remains challenging [12]. Additionally, balancing internationalization and increasing class sizes [13] makes the teaching and learning situations more complex. These are both threats as well as opportunities for teachers to adopt pedagogies or approaches related to engagement.

To address the challenges of better engaging university students for quality learning experiences and increasing teachers' chances of adopting the necessary changes, improving the physical learning spaces for interactive teaching and learning was deemed a viable strategy. Literature on "Learning Space Design" indicates growing trends of learner-centered principles to support multiple types of learning including active, cooperative, and collaborative learning. Projects on this type of learning space design aim to transform existing spaces into reimagined spaces that connect physical and virtual worlds, in-class and out-of-class learning, as well as formal and informal learning for facilitating student engagement [14-17]. However, these projects also imply significant investments in terms of finance and manpower. A massive redesign of existing learning spaces at the institutional level has yet to be seen. Thus, a preliminary application utilizing the iBeacon/Bluetooth Low Energy Beacon Technology was developed to create an innovative system-level enabler, which is economical and easy to adopt, in order to enrich existing physical learning spaces on campus for engaging learning experiences.

\section{1 iBeacon Technology in the Classroom}

In the current generation of Bring Your Own Device (BYOB), iBeacon Technology can be embedded in different existing physical learning spaces (i.e. lecture halls, seminar rooms, general teaching rooms, laboratories, libraries) with virtual activities or simple e-activities through the iBeacon transmitters and the companion mobile application. The goal of which is to allow students to become active explorers through accessing the e-materials organized by teachers. As both Android and iOS systems are reported to cover $99.7 \%$ smartphone market shares all over the World by May 2017 [18], this type of technology is accessible to most students.

In practice, using Bluetooth signals, when a student approaches an iBeacon transmitter, the mobile application installed on the student mobile device will prompt the information available from this iBeacon to display. This technology is not yet extensively used in educational settings and most of the applications are in the commercial and tourism sectors, e.g. for disseminating advertisements in shopping malls and displaying menus in restaurants. Applications of the technology are often primitive, but the technology supports both low tech (e.g. video, audio and web information) and high tech (e.g. AR/MR) content.

The implementation of iBeacon Technology in education could be a new dimension of “ubiquitous learning” where technology is integrated into the students' learning environment to enable easy access to learning materials anytime and anywhere [19]. An example of the effectiveness of this technology and successful implementation in an 
educational setting was Mr. Paul Hamilton, who integrated the iBeacon Technology and tablets to encourage primary school students to learn about coding and promoting the use of library facilities [20]. This technology adds an extra dimension to learning, where students are not restricted to a particular location inside the classroom or even within the classroom itself. Additionally, it allows students to physically explore their learning environment. Moreover, this technology has been used in higher education so information regarding the university's facilities could easily be disseminated [21]. This introduces the idea of a Smart Campus, as presented by Merode et al. [22] where integrating technology into the campus environment allows dynamic information distribution depending on the audience profile. Other uses of iBeacon technology in higher education are found in automatic attendance systems and iBeacon-equipped learning zones. Deugo [23] introduced an iBeacon-based automatic attendance tracking system to examine the relationship between attendance and academic performance in higher education science students. McDonald and Glover [24] developed a mobile application for art and design students with functions providing training resources, sharing learning materials set by tutors, and a peer review system in different zones of their university's studios. Feedback from students indicated that they built a better relationship with the tutors through the project and were more open to learning inside and outside formal teaching sessions.

iBeacons can also offer more information, allow downloadable videos, track student attendance, and offer information specific to the student's location (e.g. explanation to use of equipment inside laboratories). Although there may be many potential use cases of the iBeacon Technology in educational settings, there are very few published studies in this area. This paper presents the preliminary steps of a creating a mobile application utilizing iBeacon Technology as an innovative enabler to enrich existing physical learning spaces for engaging learning experiences in higher education.

\section{2 iClassPolyU}

\subsection{Development}

A preliminarily mobile application with a companion side client web application was developed in-house for an initial system evaluation. This system was named "iClassPolyU”. The client-side web application allowed educators to interact with students by viewing the attendance, participants' questions, and the class discussions. Additionally, educators could upload educational materials for students to access (Figure 1). The mobile application used Bluetooth Low Energy (BLE) to implement location-based services (LBS) for information delivery to medium and large-scale classes and included several functions such as attendance, quiz, groups, and discussion (Figure 2). Students could register on the platform with their student email accounts. The QR code to download the application was available on an instruction card and distributed to all participating students in the class. The mobile application was also available in App Store for iOS [25] and Google Play Store for Android [26] systems. 


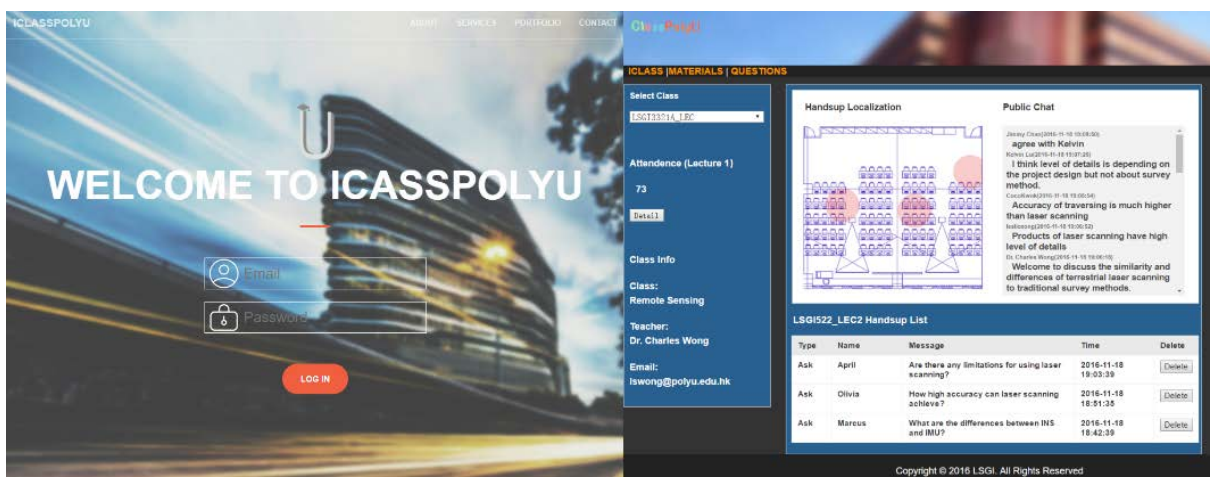

Fig. 1. "iClassPolyU” client web application.

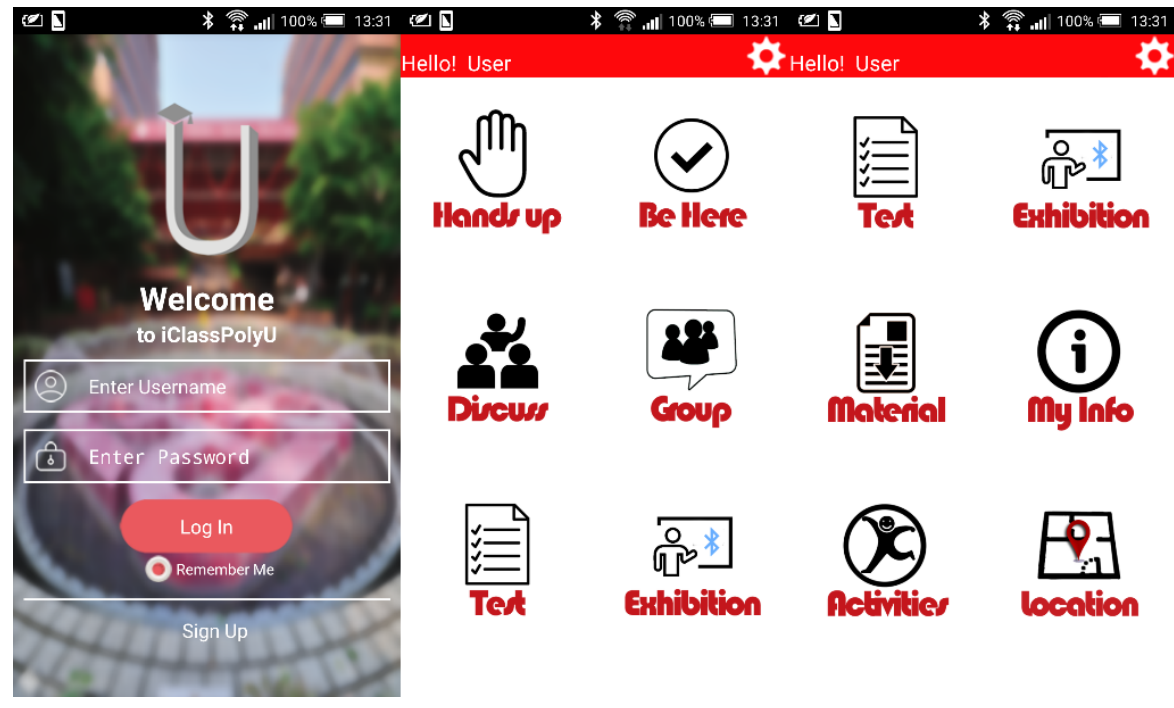

Fig. 2. "iClassPolyU” mobile application.

\subsection{Implementation}

Research was conducted in two phases in October 2017 and November 2017, respectively. In the first phase, two large-scale classes utilized "iClassPolyU" in their classrooms. In the second phase, two medium-scale classes used the system. The application's functions such as test, group, and discussion were implemented in the pilot as well as the indoor positioning system. The location-based services in the classroom were installed with a set of Estimote iBeacons. The learning materials were disseminated and published on the "iClassPolyU" platform by the educators.

Students scanned the QR code from the instruction card and downloaded the "iClassPolyU” application through the Apple App Store or Google Play Store directly. They then registered the application using their university email accounts. Students would select the "Be Here" button to record their attendance. Afterwards, they would access 
the test page to finish the online quizzes. Students completed the quizzes immediately after the lectures. These quizzes aimed to strengthen the students' knowledge on the topic. Meanwhile, the educator could check how many students were completing the quizzes and the attendance list would be shown on the web-based platform.

\section{$2.3 \quad$ Evaluation}

The quality and effectiveness of learning was evaluated by several measures surrounding student usage. These were the rate of participation, interactions, motivations, and adaptability. There were two data collection methods. First, data was collected by the application regarding usage: rate of participation, quiz completion rates, and quiz performance. These data were presented with simple statistics. Second, the student perceptions of the application were investigated through an online survey utilizing Likert Scale questions and evaluated using the Technology Acceptance Model (TAM) in the areas of perceived usefulness, perceived ease of use, attitude towards usage, and the behavioral intention to use the mobile application.

The online survey was carried out in order to collect feedback from students directly. The survey was based on an initial round of pilot work, with modifications to fit the specific context of the "iClassPolyU" usage and subsequently developed from the TAM scales, adapted from Davis [27] and Venkatesh et al. [28]. The survey consisted of two multiple-choice questions and 12 Likert scale questions. These scale questions measured the "perceived usefulness" (three questions), "perceived ease of us" (three questions), "attitude to usage" (four questions), and "attitude to technology" (four questions). The response scale for all items was a five-point Likert scale where 5 = strongly disagree, 4 = disagree, 3 = neutral, 2 = agree, and $1=$ strongly agree. Finally, Cronbach's Alpha was used to assess the internal consistency of the scales.

\section{Results}

\subsection{Participating Courses}

The application was utilized in large (Course 1 and 2) and medium-sized classes (Course 3 and 4) and participant numbers per class ranged from 95-14. This was due to class attendance on the day of pilot implementation. For instance, many of the classes had approximately 50-75\% attendance on the day of pilot implementation. Additionally, participation in this study was voluntary. In the largest class, 97 students attended the first day and 95 of those students participated in the research. A total of 188 students used the application during the research period.

\subsection{Usage}

As stated previously, materials in the application were based on the classroom topics. Each course had a different number of quizzes. For Course 1, 2, 3, 4, there were eight, five, seventeen, and seventeen quizzes available to students, respectively. The quiz completion rate for all four courses was over $84 \%$ (see Table 1 ). 
Table 1. Participators of completion rate.

\begin{tabular}{lllll}
\hline & $\begin{array}{l}\text { Course 1 } \\
(\mathrm{n}=95)\end{array}$ & $\begin{array}{l}\text { Course 2 } \\
(\mathrm{n}=41)\end{array}$ & $\begin{array}{l}\text { Course 3 } \\
(\mathrm{n}=38)\end{array}$ & $\begin{array}{l}\text { Course 4 } \\
(\mathrm{n}=14)\end{array}$ \\
\hline $\begin{array}{l}\text { Number of Participator’s } \\
\text { Completion Rate }\end{array}$ & $91.4 \%$ & $89.8 \%$ & $95.8 \%$ & $84.3 \%$ \\
\hline
\end{tabular}

When analyzing quiz performance between the large and medium-scale classes, the performance of students in the large-scale class was lower than performance in the medium-scale class. Additionally, the standard deviation in quiz performance was calculated. The large-scale class had a standard deviation in quiz score of 0.18 and the medium-scale class had a standard deviation of 0.21 . The analysis of the standard deviations demonstrated that the large-scale class had less of variation in quiz grades than the medium-scale class.

\subsection{Perceptions}

The TAM based survey was returned by 52 participants via the "iClassPolyU” application. A reliability analysis was conducted in order to check the internal consistency of the items used to monitor each factor (Table 2). The overall Cronbach's Alpha score was 0.89 , showing a good internal consistency.

Table 2. Reliability Analysis.

\begin{tabular}{lll}
\hline Factors & Items & $\begin{array}{l}\text { Cronbach's } \\
\text { alpha }\end{array}$ \\
\hline Perceived usefulness & 3 & 0.74 \\
Perceived ease of use & 2 & 0.59 \\
Attitude of usage & 4 & 0.78 \\
Behavioral intention to use system & 3 & 0.72 \\
\hline
\end{tabular}

The importance of factors related to TAM for student participants was investigated. When comparing the four factors, perceived usefulness and ease of use were of most concern to students when using "iClassPolyU” (48\% of respondents and $42 \%$ respondents, respectively). Overall, student feedback regarding the application tended to be positive. Particular aspects within the four factors were noted as exceptionally important to students. Students believed that the application would improve their learning and participation in class and that the ability to observe the progress of their learning performance with the compatibility of smart devices was vital. Additionally, students reported that the application was effective in achieving their learning outcomes, easy to use, and flexible. Finally, students reported they were willing to continue to use the application as a complementary tool in their learning.

Furthermore, information on the future functionality for the application was investigated with multiple choice questions where respondents could only choose one answer. Students identified three functions which they believed would enhance the application and they would like to see in the application in the future. These features are Virtual 
Reality (29\% of participants), Augmented Reality (27\% of participants), and Mixed Reality (37\% of participants).

\section{Discussion}

This study investigated three main areas when implementing the "iClassPolyU" application in two large-sized and two medium-sized classrooms: usage, perceptions, and future uses. Over $84 \%$ of students who were invited to participate on the implementation days in the classroom completed all the quiz tasks available in the application. While there were differences in student quiz scores, a smaller standard deviation in scores was identified in the large-sized classrooms than in the medium-sized classrooms. Normally, large classes have more issues related to teaching and learning than smaller classes [13]. Yet, when the "iClassPolyU" application was utilized in the classroom, fewer differences in learning were identified in the large-scale class than the medium-scale class. This illustrates that with proper implementation, modern technology with the location-based systems may encourage student-student interaction and enhance the motivation to learn, thus reducing the learning differences in a class.

Additionally, perceptions on the application were collected via a TAM-based survey. Past research has shown that perceived ease of use and perceived usefulness are the most vital aspects in adoption of e-learning materials [29]. This research is mirrored by the findings presented in the results section. Overall, students felt that their physical participation could be enhanced using the mobile application in the classroom and agreed that the platform was effective in assisting them to achieve their learning goals. Moreover, they found the mobile application to be easy to use and flexible. Furthermore, students reported that they were willing to continue using the application to support their classroom learning, showing a general acceptance of "iClassPolyU”.

Finally, students felt that the application could be improved with features such as virtual reality, augmented reality, and mixed reality. These additional features would be able to augment different existing physical learning spaces such as the classroom with virtual activities or simple e-activities for facilitating engaging learning experiences [30,31].

\section{Conclusion}

This paper presents findings surrounding student usage of a preliminary mobile application using iBeacon/BLE Beacon Technology. By creating mobile applications for engaging active physical learning spaces, a new pathway for student learning is created which in turn may assist them in meeting their learning goal if appropriately integrated into their learning environment. Additionally, immediate feedback from the quizzes allows students to evaluate their performance and assist in self-identification of weaknesses. Applications such as these, especially ones that use iBeacon technology to provide classroom specific information, have the opportunity to revolutionize the classroom experience and give students more control over their learning while providing educators with more information about their students. 
In the future, the application outlined in this paper will be enhanced to include more advanced functionality such as automatic attendance record taking, self-learning activities such as location-based videos, communication tools for student groups, adaptive learning support, and AR/VR/MR. Student learning will then be investigated, and findings will be used to support better systems and assist in learning space design to enhance the learning experience

Acknowledgments. This project was supported in part by "New Mobile Learning Scenarios Enabler - Development of Location-based Driven Application for Innovative and Technology-assisted Teaching and Learning Using iBeacon Technology” from the eLearning and Blended Learning Development Fund 2014-17, the Hong Kong Polytechnic University, Hong Kong; and “Augmenting Physical Learning Spaces with Location-based Services Using iBeacon Technology for Engaging Learning Experiences”, UGC Funding Scheme for Teaching and Learning Related Proposals (2016-19 Triennium), University Grants Committee, Hong Kong.

\section{References}

1. Leach, L.: Exploring Discipline Differences in Student Engagement in One Institution. Higher Edu. Res. Develop. 35(4), 772--786 (2016)

2. Pascarella, E.T., Terenzini, P.T.: How College Affects Students: A Third Decade of Research. Jossey-Bass, San Francisco (2005)

3. Russell, J.E., VanHorne, S., Ward, A.S., Bettis III, E.A., Sipola, M., Colombo, M., Rocheford, M.K.: Large Lecture Transformation: Adopting Evidence-Based Practices to Increase Student Engagement and Performance in an Introductory Science Course. J. Geosci. Edu. 64(1), 37-$51(2016)$

4. Tinto, V.: Leaving College: Rethinking the Causes and Cures of Student Attrition (2nd ed.). University of Chicago Press, Chicago (1994)

5. Trowler, V., Trowler, P.: Student Engagement Evidence Summary. Higher Education Academy, York, UK (2010)

6. Chickering, A.W., Gamson, Z.F.: Seven Principles for Good Practice in Undergraduate Education. AAHE Bull. 39, 3--7 (1987)

7. Svinicki, M.D., Schallert, D.L.: Learning Through Group Work in the College Classroom: Evaluating the Evidence from an Instructional Goal Perspective. In: Higher Education: Handbook of Theory and Research, pp. 513--558. Springer (2016)

8. Crouch, C.H., Mazur, E.: Peer Instruction: Ten Years of Experience and Results. A. J. Phys. 69(9), 970--977 (2001)

9. Kam, R., Tang, S.K., Lee, L.: The Impact of Technology-supported and Triangulated Writing Tasks on a Pilot Interdisciplinary Undergraduate Subject for Construction Disciplines. Comp. Comp. 40, 131--150 (2016)

10.Bonwell, C.C., Eison, J.A.: Active Learning: Creating Excitement in the Classroom. In: 1991 ASHE-ERIC Higher Education Reports. ERIC Clearinghouse on Higher Education, The George Washington University, Washington (1991)

11.Smith, K.A., Sheppard, S.D., Johnson, D.W., Johnson, R.T.: Pedagogies of Engagement: Classroom-based Practices. J. Eng. Edu. 94(1), 87--101 (2005)

12.Coates, H.: The Value of Student Engagement for Higher Education Quality Assurance. Q. Higher Edu. 11(1), 25--36 (2005) 
13.Hyland, K.: Re-imagining Literacy: English in Hong Kong's New University Curriculum. In: English Language Education and Assessment, pp. 139--151. Springer, Singapore (2014)

14.Groff, J.: Technology-rich Innovative Learning Environments. Project Report, OCED CERI Innovative Learning Environment Project (2013)

15.JISC: Designing Spaces for Effective Learning http://www.jisc.ac.uk/media/documents/publications/learningspaces.pdf

16.Oblinger, D.: Leading the Transition from Classrooms to Learning Spaces. Educause Q. 28(1), 14--18 (2005)

17.Oliver, G.: Developing New Learning Environments. In: Evaluating Learning Environments, pp. 107--115. SensePublishers, Netherlands (2016)

18.International Data Corporation: Smartphone OS Market Share, 2017 Q1, http://www.idc.com/prodserv/smartphone-os-market-share.jsp

19.We, Y., Young, L., Wen, M.: Developing an iBeacon-based Ubiquitous Learning Environment in Smart Green Building Courses. Int. J. Eng. Educ. 32(2), 782--789 (2016)

20.JNXYZ Education: Video of First School-Implementation of iBeacons, http://jnxyz.education/beaconsforeducationblog/2014/3/30/video-of-first-school-implementation-of-ibeacons

21.University of Bradford: About UoB, http://www.brad.ac.uk/it-services/students/mobile-technology/about-uob/

22.Merode, D., Tabunshchyk, G., Patrakhalko, K., Yuriy, G.: Smart Campus based on iBeacon Technology. In: International Symposium on Ambient Intelligence and Embedded Systems. Oostende, Belgium (2015)

23.Deugo, D.: Using Beacons for Attendance Tracking. In Proceedings of the International Conference on Frontiers in Education: Computer Science and Computer Engineering (FECS), pp. 155--161. CSREA Press: LAS (2016)

24.McDonald, K., Glover, I.: Exploring the Transformative Potential of Bluetooth Beacons in Higher Education. Res. Learn. Tech. 24 (2016)

25.Lu, K.: iClassPolyu, https://itunes.apple.com/us/app/iclasspolyu/id1166861954?l=zh\&ls=1\&mt=8

26.LSGI, The Hong Kong Polytechnic University: iClassPolyU, https://play.google.com/store/apps/details?id=com.kelvin.lu.tealea\&hl=zh-CN

27.Davis, F.D.: Perceived Usefulness, Perceived Ease of Use, and User Acceptance of Information Technology. MIS Q. 13(3), 319--339 (1989)

28.Venkatesh, V., Morris, M.G., Davis, G.B., \& Davis, F.D.: User Acceptance of Information Technology: Toward a Unified View. MIS Q. 425--478 (2003)

29.Park, S.Y.: An Analysis of the Technology Acceptance Model in Understanding University Students' Behavioral Intention to Use e-learning. Edu. Tech. Soc. 12(3), 150--162 (2009)

30.Dede, C.: Immersive Interfaces for Engagement and Learning. SCIENCE 323(5910), 66--69 (2009)

31.Alexandros. P., Christos. A.: A Mobile Augmented Reality (mAR) Blended Learning Application for Primary School Pupils. In: Blended Learning for 21st Century Learner - 1st International Association for Blended Learning Conference (IABL 2016). ResearchGate: Kavala, Greece (2016) 